\title{
A systematic review of the outcomes of osteoporotic fracture patients after hospital discharge: morbidity, subsequent fractures, and mortality
}

\author{
Ahmad Shuid Nazrun' \\ Mohd Nizam Tzar² \\ Sabarul Afian Mokhtar \\ Isa Naina Mohamed' \\ 'Department of Pharmacology, \\ ${ }^{2}$ Department of Medical Microbiology \\ and Immunology, ${ }^{3}$ Department of \\ Orthopedic, Universiti Kebangsaan \\ Malaysia Medical Centre, Kuala \\ Lumpur, Malaysia
}

\author{
This article was published in the following Dove Press journal: \\ Therapeutics and Clinical Risk Management \\ 18 November 2014 \\ Number of times this article has been viewed
}

Purpose: Osteoporotic fracture is the main complication of osteoporosis. The current management is to discharge patients as early as possible so they can get back to their daily activities. Once discharged, there are three main issues relating to morbidity, mortality, and risk of a subsequent fracture that need to be addressed and discussed. Therefore, the aim of this systematic review was to summarize and evaluate the evidence from published literature, to determine the outcome of osteoporotic fracture patients after their hospital discharge.

Methods: The MEDLINE and Cumulative Index to Nursing and Allied Health Literature (CINAHL) databases were searched, using the terms "osteoporosis", "fracture", "osteoporotic fracture", "hip fracture", and "vertebral fracture". We included only human studies published in English between 2004 and 2014. The reference lists of included studies were thoroughly reviewed in search for other relevant studies.

Results: A total of 18 studies met the selection criteria. Most were observational and cohort studies. Out of all the studies, five studies looked into the morbidity, six studies looked into the risk of subsequent fractures, and seven studies looked into mortality. Vertebral fracture caused the greatest health burden, but hip fracture patients were the main users of informal care after hospital discharge. There was an increased risk of a subsequent fracture after a primary fracture compared with the control group, a cohort comparison, or the general population. Osteoporotic fractures, especially hip fractures, are associated with higher mortality rate despite the advances in the management of osteoporotic fracture cases.

Conclusion: There is strong evidence to show that after hospital discharge, osteoporotic fracture patients are faced with higher morbidity, subsequent fractures, and mortality.

Keywords: osteoporosis; hip fracture, vertebral fracture

\section{Introduction}

Osteoporosis is defined as deterioration in bone mass and architecture resulting in weakness of the bone, which is then prone to fracture. The major complication is osteoporotic fracture, which occurs with minimal trauma, such as a simple fall from standing height or less. Osteoporotic fracture is also known as low-trauma, nontraumatic, or fragility fracture. Fractures in elderly have caused significant impact on the community health. ${ }^{1}$ Approximately $50 \%$ of women and $22 \%$ of men over the age of 50 will experience an osteoporotic fracture in their lifetime. ${ }^{2,3}$ The high incidence of fractures in the elderly aged 50 years and above may be contributed by weakness of the bone due to osteoporosis. ${ }^{4,5}$ The incidence of osteoporosis is on the rise due to
Correspondence: Ahmad Shuid Nazrun Department of Pharmacology, Faculty of Medicine, National University of Malaysia, 17th Floor, Preclinical Building, Jalan Yaacob Latif, Bandar Tun Razak, 56000 Cheras Kuala Lumpur, Malaysia Tel +60391459545

Fax +60 326938205

Email anazrun@yahoo.com 
the aging society. People are living longer with better health services, but their bone mineral density is likely to deteriorate with aging or other secondary causes, thus increasing the risk of osteoporotic fractures. The main osteoporotic fracture sites are hip, spine, and wrist, while other less common sites are forearm, ribs, and pelvis. Following an osteoporotic fracture, the patient is exposed to several adverse outcomes, which can be divided into three broad categories: morbidity, risk of subsequent fracture, and mortality.

Morbidity is defined as the state of being diseased or unhealthy within a population. Osteoporotic fracture is associated with significant morbidity, which may adversely affect the patient's socioeconomic, physical, and psychological well-being. The negative implications of the patient's morbid condition may also encroach into their caretaker's life. This is more likely to happen with the current practice of early hospital discharge into the care of family or relative, to reduce hospitalization cost, reduce the risk of nosocomial infections, and promote recovery in their home environment. Therefore, research is necessary to develop a better understanding of the impact of osteoporotic fracture on health burden and decline of function after patients are discharged to their home. ${ }^{6}$

Of all the osteoporotic fractures, hip fracture has been given the most attention. There are many reports on the personal burden of hip fracture, especially in terms of limited mobility. ${ }^{7,8}$ One study found that about $50 \%$ of elderly women with hip fracture lost the ability to walk independently. ${ }^{9}$ Similarly, another found that about $50 \%$ of women with hip fracture lost their independence and required long-term care or help in carrying out their daily activities. ${ }^{10}$ In another study, up to one-third of hip fracture patients became totally dependent on their family members and relatives. ${ }^{11}$ The burden due to hip fracture was frequently reported, although it represented less than half of all fractures in elderly over 80 years old. ${ }^{7,8}$

The incidence of vertebral fractures is 1.4 million cases worldwide, which affects $25 \%$ of postmenopausal women and $40 \%$ of women aged 80 years and older. ${ }^{12,13}$ The risk of sustaining a vertebral fracture is higher in women, with $15.4 \%$ lifetime risk for women and $8.6 \%$ for men older than 45 years old. ${ }^{14}$ The prevalence of vertebral fractures increases with age for both sexes. ${ }^{15}$ As compared with hip fracture, there are limited reports on vertebral fractures, which may result in underestimation of the burden that they impose. ${ }^{16}$ The major burden faced by patients with vertebral fracture is back pain, which may last for a few weeks to months or longer. ${ }^{17,18}$ They may also experience functional difficulties, kyphosis, and height loss. The interference of the patient's daily activities due to vertebral fracture was found to be comparable with that of hip fractures. ${ }^{19}$

It was found that just as in hip and vertebral fractures, wrist fractures may, to some degree, interfere with the ability to perform daily activities, such as cleaning up and cooking. In isolated cases, patients are completely disabled by a wrist fracture. ${ }^{20}$ About half of the wrist fracture patients reported only fair or poor functional outcomes at 6 months postfracture. $^{21}$

The impact of osteoporotic fracture is not restricted to physical burden and may also result in psychological consequences. However, there are very few studies on the psychological impact of fracture on the patient. The patients may suffer low self-esteem, impaired body image and mood changes. ${ }^{22}$

Osteoporosis fracture recovery may take time and incur significant burden in health costs. ${ }^{23}$ The management of osteoporotic fractures places significant burden to formal health care, such as hospitalizations, rehabilitative and long-term care, and informal care. ${ }^{24,25}$ According to the current fracture management protocol, patients are discharged from the hospital earlier to reduce costs and risks of nosocomial infections from lengthy hospital stay. This shifts the fracture management and costs to rehabilitation in the community.

It was reported that hospitalizations for fractures, particularly hip fractures, represent only a portion of the burden of fractures. ${ }^{1}$ Wiktorowicz et $\mathrm{al}^{27}$ reported that the cost of initial hospitalization of hip fracture cases may represent only $27 \%$ of total costs of management, while the costs of managing this patient after discharge from the hospital may account for $69 \%$ of 1 -year costs postfracture. The main cost of rehabilitation for hip fracture was estimated to be $59 \%$ of all costs and was mainly spent for stays at nursing homes and rehabilitation centers, as well as outpatient and home physical therapy sessions. ${ }^{28}$ Therefore, merely focusing on the costs of acute care of fractures could underestimate the financial burden related to fractures.

Osteoporotic patients have higher risk for subsequent fractures, which are associated with an even greater increase in mortality rates and a significantly higher cost. ${ }^{29}$ Despite substantial evidence that a prior fracture resulted in an increased risk of subsequent fracture, less than $30 \%$ of postmenopausal women and less than $10 \%$ of men with prior fracture receive prophylactic treatment. ${ }^{16,30,31}$

Mortality is the term used for the number of people who died within a population. In addition to compromising the quality of life, fractures are associated with 
increased mortality. ${ }^{32,33}$ For the past decade, the trend for hip fracture management has shifted toward surgical approach, with more and more patients ending up by receiving a hemiprosthesis. With the significant advancement in management of patients with hip fracture, there is a need to review more recent studies to analyze the impact of osteoporotic fractures on mortality rate of its sufferers.

The objective of this systematic review was to determine the outcome of osteoporotic fracture patients after their hospital discharge. Most studies have focused on various aspects of osteoporotic fracture cases while they were managed in the hospital. This review concentrates on the patient outcomes of osteoporotic fracture after they were discharged from the hospital.

\section{Material and methods Search strategy}

For a comprehensive search of health science journals, we used MEDLINE, via Ovid MEDLINE, and Cumulative Index to Nursing and Allied Health Literature (CINAHL), via EBSCOhost. The databases were accessed from March 12 to March 20, 2014. The search strategy involved a combination ("AND") of the following three sets of key words: 1) osteoporo* OR osteopen*; 2) hip OR fem* OR spin* OR verteb*; and 3) fracture* OR broke*. Furthermore, the references of all retrieved articles were reviewed for relevant citations.

\section{Inclusion criteria}

All adult human cohort and case-control studies with abstracts that investigated the adverse outcome of osteoporotic fracture cases after discharge from the hospital were included. These included studies of morbidity, mortality, and risk of subsequent fracture. In addition, only studies published within the last 10 years, from 2004 to 2014, were included, to ensure up to date evidence. Due to limited resources, only manuscripts written in English were included in this review.

\section{Exclusion criteria}

Case reports, case series, animal studies, letters to the editor, and review articles were excluded. This review focused on the outcome of patients with osteoporotic fractures after they were discharged from the hospital. Therefore any studies on management of osteoporotic fracture cases within the hospital, such as studies of surgeries, use of drugs, or multidisciplinary approaches were excluded.

The selection criteria were used to achieve the objective of this systematic review in determining the adverse outcome faced by osteoporotic fracture patients after their discharge from the hospital.

\section{Screening of articles for eligibility}

Retrieved articles were screened in three phases. In the first phase, any article with titles that did not match the inclusion criteria was excluded. In the second phase, the abstracts of the remaining articles were screened, and any articles that did not meet our inclusion criteria were excluded. In the final phase, full texts of the remaining articles were read and assessed thoroughly to exclude articles that did not meet our inclusion criteria or articles that fulfilled the exclusion criteria. Systematic reviews or meta-analysis were also excluded. Duplicates were removed. All the authors were involved in the selection and the data extraction phase. Any differences in opinions were resolved by discussion between the authors. In order to standardize the data collection, all data extraction was performed independently using a data collection form. A flow chart that summarizes the article selection process and the reasons for article exclusion is shown in Figure 1.

\section{Data extraction}

The following data were extracted from the selected studies: (1) author/study name; (2) study design; (3) study objective; (4) outcome parameters measured; (5) study population; (6) methodology; (7) results; and (8) conclusion. The relevant and, particularly, significant statistical values were recorded (odds ratio, hazard ratio [HR], and $P$-value).

\section{Results}

Based on the studies included, the outcomes were classified into three major classes; morbidity, subsequent fractures, and mortality. A total of 18 studies met the eligibility criteria. Most of the studies were observational and cohort studies. The number of studies originating from each continent was as follows: three from America, nine from Europe, two from Asia, and four from Australia and New Zealand. The morbidity classification included a study that involved several European countries (France, UK, Spain, Italy, and Belgium). ${ }^{28}$ The rest of the studies were carried out in Canada, ${ }^{34}$ Iceland, ${ }^{35}$ Japan,,${ }^{15}$ and Sweden. ${ }^{36}$ The subsequent fracture classification included studies from Taiwan, ${ }^{37}$ Australia and New Zealand, ${ }^{38}$ United States, ${ }^{39}$ New Zealand, ${ }^{40}$ Australia, ${ }^{41}$ and Sweden. ${ }^{42}$ The mortality classification included studies from Denmark, ${ }^{45}$ Australia, ${ }^{46}$ Canada, ${ }^{47}$ Sweden, ${ }^{48,51}$ France, ${ }^{49}$ and Sweden ${ }^{51}$.

The morbidity classification measured outcome parameters in term of rehabilitative cost, ${ }^{28}$ use of formal and informal care, ${ }^{34}$ 


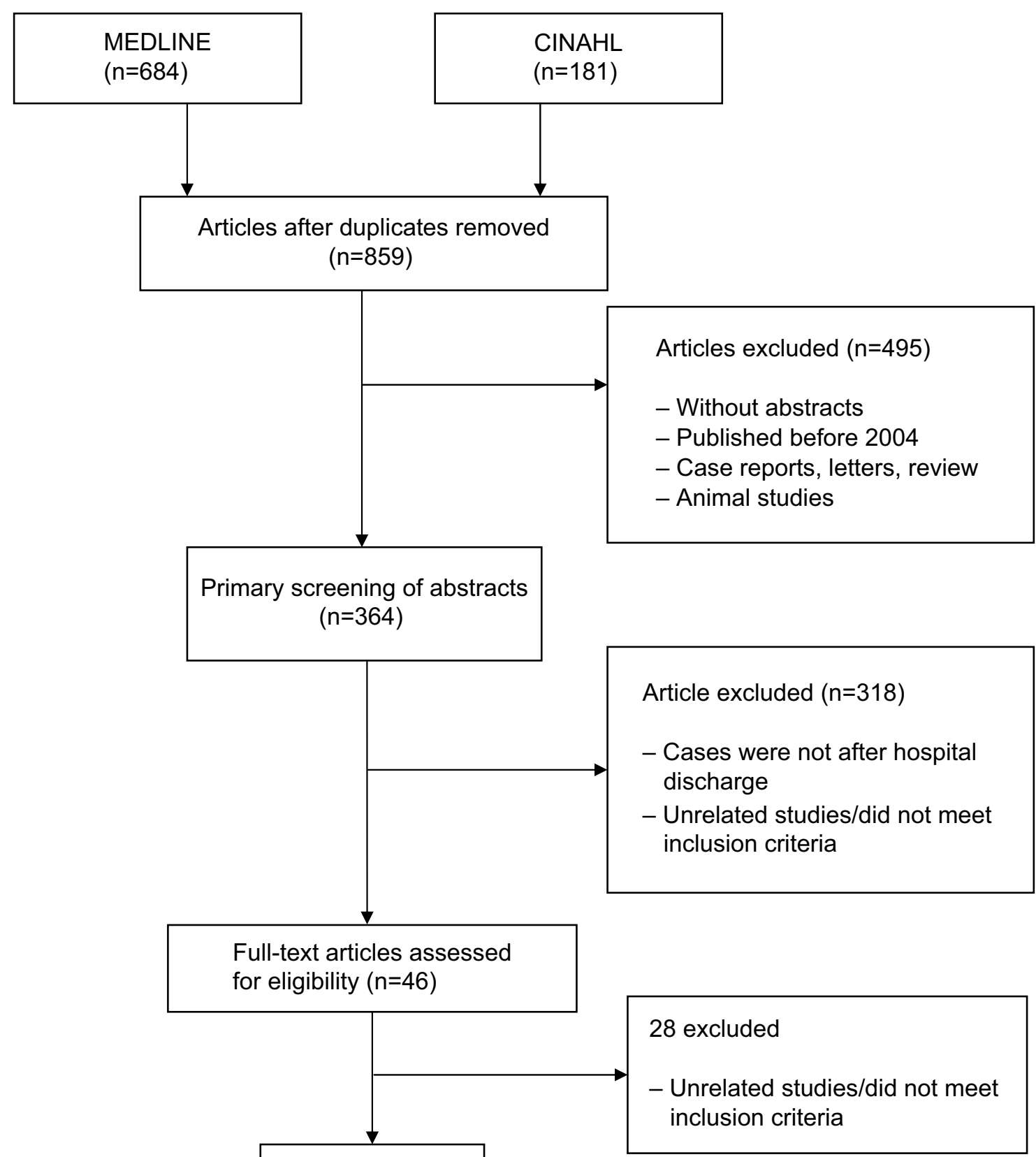

18 articles

Figure I The algorithm for selection of studies in this systematic review.

Abbreviation: CINAHL, Cumulative Index to Nursing and Allied Health Literature.

function and subsequent risk of hospitalization, ${ }^{35}$ destination after hospital discharge, ${ }^{15}$ and health-related quality of life (HRQOL). ${ }^{36}$ The subsequent fracture classification measured outcome parameter in terms of risk of subsequent fracture ${ }^{37,38,41,42}$ and HR of subsequent fracture. ${ }^{39,40}$ The mortality classification measured outcome parameter in terms of mortality rate, ${ }^{45,48,49}$ standardized mortality ratio, ${ }^{46}$ ageand risk-adjusted mortality, ${ }^{47}$ postoperative mortality, ${ }^{50}$ and mortality risk. ${ }^{51}$
All studies involved osteoporotic fracture patients. Table 1 highlights the findings of the selected studies.

\section{Morbidity}

The morbidity faced by osteoporotic fracture patients after discharged from hospital was assessed based on functional and mobility tests, questionnaires, risk of hospitalization, and use of postdischarge informal care. ${ }^{15,28,34-36}$ Siggeirsdottir et $\mathrm{a}^{35}$ assessed the effect of vertebral and other osteoporotic 


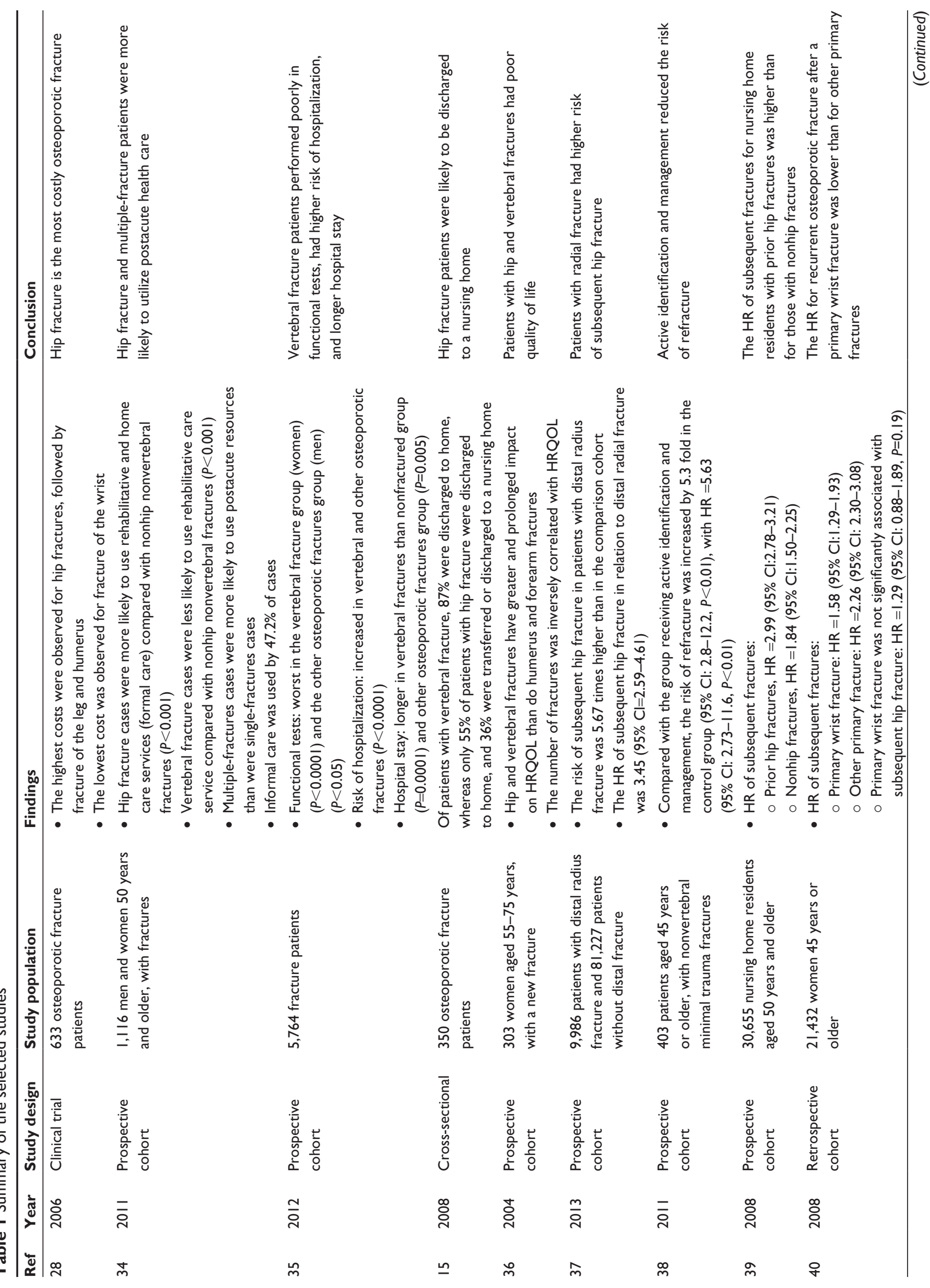




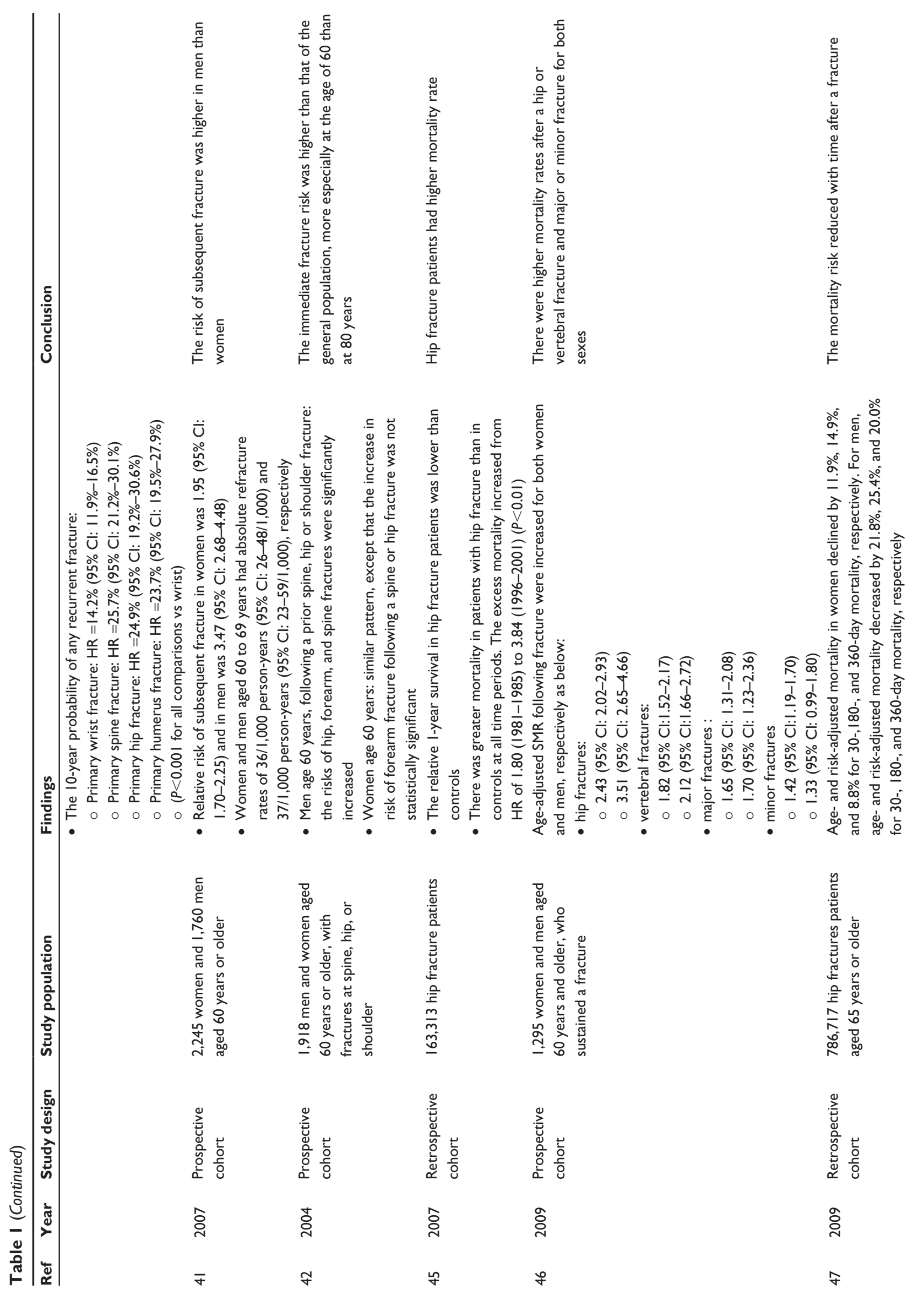


fractures on function and quality of life and subsequent risk of hospitalization. Functional capabilities were measured with the Timed Up and Go test, the 6-meter walk, handgrip and quadriceps strength, and activity of daily living questionnaire. Quality of life was assessed with the EuroQol five dimensions (EQ-5D) questionnaire. Vertebral fracture participants had poorer functional capabilities and quality of life compared with nonfractured and other osteoporotic fracture groups.

Hallberg et $\mathrm{al}^{36}$ evaluated the HRQOL of elderly women with a new fracture, using the 36-Item Short Form Health Survey (SF-36) questionnaire. Women with hip or vertebral fracture were found to have poorer HRQOL than with humerus or forearm fracture. The impact of hip and vertebral fractures on HRQOL was also prolonged. Multiple fractures were associated with worse HRQOL.

Vertebral fracture patients contributed to the highest percentage of another hospitalization and longer hospital stay. ${ }^{35}$ The main cause of hospitalization was having another fracture. The risk of hospitalization was higher if the vertebral fracture had occurred less than 10 years previously. Therefore, compared with other types of osteoporotic fractures, vertebral fracture resulted in higher risk of hospitalization and longer hospital stay. In terms of destination after discharge from hospitals, $87 \%$ of patients with vertebral fracture were discharged to home. Only $55 \%$ of patients with a hip fracture were discharged to home, while $36 \%$ were transferred or discharged to a nursing home. The average hospitalization period was 30.5 days for a hip fracture and 20.4 days for a vertebral fracture. ${ }^{15}$

Kaffashian et $\mathrm{a}^{134}$ examined the utilization of informal care by osteoporotic fracture patients after hospital discharge. Hip fracture patients had greater tendency to use rehabilitative and home care services, with almost $70 \%$ reporting use of rehabilitative services. In comparison, only $25 \%$ of the vertebral fracture patients used the rehabilitative services.

In term of home care services, which included nurse home visits or homemaker services, about $50 \%$ of the hip fracture patients had used these services. In contrast, only about $15 \%$ of the vertebral fracture patients had used the services.

It was calculated that nearly $76 \%$ of the hip fracture patients had used either the rehabilitative services or the home care services, while only about $30 \%$ of the vertebral fracture patients had used either service. As for patients of other types of osteoporotic fracture, about $35 \%$ had used the rehabilitative services, $14.3 \%$ the home care services, and $37.4 \%$ had used either service.

The longer hospital stay and rehabilitative services for fracture patients require extra costs. In a study on the 
rehabilitation costs after nonvertebral fractures, involving five European countries, the highest costs were observed for hip fractures, followed by fractures of the leg (tibia, fibula, and femur but not hip) and the humerus. The lowest cost was observed for fracture of the wrist. ${ }^{28}$

\section{Subsequent fracture}

Once osteoporotic patients experience primary fractures, they are at risk of getting a subsequent fracture. There were six studies that assessed the risk of subsequent fractures after an osteoporotic fracture. Most of the studies focused on certain types of fracture, for eg, radius, or classify fractures into groups, for eg, nonvertebral or nonhip fractures. ${ }^{37-39}$ Only one study has examined the subsequent fracture risks for all types of osteoporotic fractures. ${ }^{40}$

All studies demonstrated an increased risk of a subsequent fracture after a primary fracture compared with the control group, a cohort comparison, or the general population. The risk of subsequent hip fracture in patients with distal radius fracture was 5.67 times higher than that in the comparison cohort, with the HR of $3.45 .{ }^{37}$ Patients with previous nonvertebral minimal trauma fracture had 5.3-fold increases in getting another fracture with the usual primary care follow-up. The 10-year probability of a subsequent fracture was found to be higher if the primary osteoporotic fracture occurred at the spine, hip, or humerus. ${ }^{40}$

One study found that nursing home residents with history of hip fractures had three times higher risk of subsequent fractures, while those with history of nonhip fractures had 1.8 times higher risk of subsequent fractures. ${ }^{39}$ In a population cohort study, following an initial osteoporotic fracture (hip, vertebral, upper limb, ribs, or lower limb), the relative risks of subsequent fracture in men and women were 3.47 and 1.95, respectively. ${ }^{41}$ The risks of subsequent fracture following a prior fracture at the spine, shoulder, or hip were higher than that of the general population. ${ }^{42}$

\section{Mortality}

Osteoporotic fracture-related mortality is on the rise in the aging population. ${ }^{43}$ Osteoporosis is a major public health problem, leading to fractures and associated mortality. Most of the studies on mortality related to osteoporotic fractures have focused on hip fractures as the numbers of elderly people with fractured neck of the femur are increasing in the world population. Despite the extra attention given and the advancement in patient management, the case fatality rates after fractured neck of femur have not declined appreciably. $^{44}$
Vestergaard et $\mathrm{al}^{45}$ analyzed registries for patients suffering hip fractures from 1981 to 2001. They found the relative 1 -year survival in patients with hip fracture was lower than in control cases. There was a significant higher mortality in women with hip fractures from 1986 to 1996 . A similar but less pronounced trend was observed in male patients. There was greater mortality, at all time periods, in patients with hip fractures than in controls. The excess mortality continued to increase, with the HR jumping from 1.80 (years 1981-1985) to 3.84 (years 1996-2001). In term of sex difference, the mortality risk was higher in men than in women.

Bliuc et $\mathrm{al}^{46}$ classified low-trauma fractures into vertebral, hip, and minor and major fractures, and studied their mortality rate in the population of Dubbo, Australia. Age-adjusted standardized mortality ratios were increased following all low-trauma fractures in both sexes. Mortality was increased for all ages and for all fractures, except for minor fractures, which was only apparent for those older than 75 years. Increased mortality risk persisted for 5 years for all fractures and for up to 10 years for hip fractures. Subsequent fracture was associated with an increased mortality HR. The mortality risk increased following a subsequent fracture then declined but remained higher than in the general population. A more detailed follow up on a group of participants revealed that the predictors of mortality after any fragility fracture for both sexes were found to be age, quadriceps weakness, and subsequent fracture. Low bone mineral density, smoking, and postural sway were also predictors for women, while low physical activity was another predictor for men. Comorbidities were not a predictor of mortality.

Brauer et $\mathrm{al}^{47}$ documented hip fracture cases from the Medicare claims from 1985 to 2005. The age and riskadjusted mortality in women were found to decline by $11.9 \%$, $14.9 \%$, and $8.8 \%$ for $30-$, 180 -, and 360-day mortality, respectively. For men, the age and risk-adjusted mortality were found to decrease by $21.8 \%, 25.4 \%$, and $20.0 \%$ for $30-$, 180-, and 360-day mortality, respectively.

Soderqvist et $\mathrm{al}^{48}$ reported that mortality rate at 4 and 24 months after a hip fracture were $16 \%$ and $38 \%$, respectively. The mortality rate was associated with high American Society of Anesthesiologists (ASA) score, low Short Portable Mental Status Questionnaire (SPMSQ) score, being elderly, and male sex.

Ziadé et $\mathrm{al}^{49}$ analyzed French death certificates from 1968 to 2004 and found that $2.2 \%$ of the reported deaths were due to osteoporotic fractures. About $1.5 \%$ of death or $69 \%$ of all osteoporotic fractures were identified as hip fracture cases. Hip fractures were the most frequent cause of 
death, followed by pelvis, vertebra, skull, ribs, and multiple fractures. Throughout the years, the mortality rates for hip fracture were higher in women than in men, but the gap in the rates between the sexes was narrowed by 2004 .

Panula et $\mathrm{al}^{50}$ followed up patients after hip fracture surgeries and reported that $79 \%$ died within 7 years. The main cause of death was circulatory system disease, which accounted for $44.1 \%$ of deaths. Most of the participants (75\%) died at the hospital, health center, or other care facility. About $25 \%$ died outside the hospital, either at home, elderly care facility, or even at an unknown place for one of the patients.

Kanis et $\mathrm{al}^{51}$ reported that the mortality risk was markedly increased immediately after fracture at all ages. The risk increased with age at a rate that was higher than that of the general population and comparable with the mortality risk 1 year after hip fracture.

\section{Discussion}

Vertebral fracture patients faced greater health burden after their hospital discharge than did those with other types of osteoporotic fracture. The fracture was associated with higher comorbidity, higher incidence of hospitalization, and longer hospital stay. These complications were especially evident in elderly men, with risks of pneumonia and musculoskeletal diseases. ${ }^{35}$

Focusing on sex, women with vertebral fractures had poorer functional capabilities compared with women without fracture or fracture at nonosteoporotic sites. Men with vertebral fracture performed poorly in quadriceps strength and Timed Up and Go test compared with men without fracture. They also scored poorly in activity of daily living questionnaires compared with men without fracture or fracture at nonosteoporotic sites. ${ }^{35}$

Vertebral fracture was associated with poorer outcome compared with other fractures, including hip fracture. ${ }^{35}$ Therefore, vertebral fracture patients were expected to be the main users of rehabilitative and home care services after their discharge from the hospitals; on the contrary, the main users of these services were found to be hip fracture patients, instead of vertebral fracture patients. ${ }^{34}$ This may be due to the fact that $88 \%$ of the hip fracture patients underwent surgery for internal or external fixation or joint replacement, thus increasing their requirements for rehabilitative and home care services after their discharge form the hospital. ${ }^{34}$

Furthermore, the main symptom of vertebral fracture, which is back pain, may vary in its intensity and may not be apparent. Sudden severe back pain may indicate vertebral fracture and should be taken seriously. However, the pain may be relatively mild or unnoticeable in some patients, thus reducing the need to use the rehabilitative and home care services after their hospital discharge.

Patients with multiple fractures were more likely to make use of the rehabilitative and home care services compared with single-fracture patients, after their discharge from the hospital. Therefore health care providers will have to be aware of the needs of multiple-fracture patients and the extra costs required in managing them. The relevant authorities also need to plan and implement strategies to prevent multiple-fracture cases.

Family members or friends may provide "informal" care while fracture patients are in the hospital or after their discharge. The informal care in hospital was minimal and limited to helping the patient to drink, stand up, get into bed, and sit. ${ }^{52}$ Extensive informal care may not be appropriate as the majority of the nursing staffs disagreed with informal inhospital care for certain chores, such as making the patient's bed, changing sheets, and performing bed baths. ${ }^{53}$

The current fracture management includes early discharge of the patient to home. The median length of stay for hip fracture decreased from 12 days in the years 1986-1988 to 5 days in the years 2003-2005. ${ }^{47}$ This has highlighted the importance of informal care for fracture patients after their discharge from the hospital. Although informal care provides valuable substitute and complement for costly formal care, there are limited studies available on this form of patient care. ${ }^{54,55}$ The care provided by informal caretakers may be done voluntarily at no charge, but there are still costs involved. The caregivers may have to take unpaid leave or forego earnings just to take care of the patient. ${ }^{56,57}$ Kaffashian et $\mathrm{al}^{34}$ reported that $36 \%$ of the caregivers had a paying job and that $25 \%$ had to take at least 1 day off to care for their relative with fracture. Thus, to get a complete and accurate understanding of the burden of fractures, studies must take into account the costs related to postacute and informal care used after the hospital discharge. ${ }^{58}$

Osteoporotic fracture is a recognized complication of osteoporosis. If another osteoporosis-related fracture occurs within a short period of time, it may result in prolonged hospitalization and considerable economic, physical, and psychological burden on society. The predictors for subsequent fractures included femoral neck bone density, age, smoking, physical activity, and calcium intake. ${ }^{41}$ Center et al ${ }^{41}$ examined the risk of subsequent fracture in both sexes. Women and men aged 60 to 69 years had absolute subsequent fracture rates of 36/1,000 and 37/1,000 person-years, respectively. 
Age is one of the critical determinants for a subsequent fracture. The minimum age for inclusion criteria in most of the studies was at least 45 years or older, except for the study by Chen et $\mathrm{al}^{37}$ which included fracture cases as young as 30 years old. Patients aged 60 years or older with primary distal radius fracture had higher incidence of subsequent hip fracture. Following a spine, shoulder, or hip fracture, the immediate risk of a subsequent fracture was markedly high for 60 -year-old subjects, even higher than that of 80 -yearold subjects. ${ }^{41}$

All the six studies on the risk of subsequent fractures included both sexes, except for Hodsman et $a{ }^{40}{ }^{40}$ who selected only female subjects. Women were noted to have higher risk of subsequent fracture than men. Chen et al ${ }^{37}$ reported that the rate ratio for subsequent hip fracture was relatively higher in women than in men. In a nursing home population, female sex was associated with increased fracture risk after an osteoporotic fracture. ${ }^{39}$ However, the absolute risk of subsequent fracture was similar for men and women. ${ }^{41}$

Some studies reported the interval at which the patients are at high risk of another fracture. The first month after a distal radius fracture was associated with the highest risk of sustaining a subsequent hip fracture. ${ }^{37}$ Johnell et al ${ }^{42}$ also reported that the risk of a subsequent fracture was at the highest immediately after sustaining an osteoporotic fracture. The median time for patients with nonvertebral fractures to have subsequent fractures was 16 months. The time increased to 26 months if the patients were referred for a coordinated intervention program. ${ }^{38}$ The risk of subsequent fracture was increased following all types of osteoporotic fractures, and the risk persisted for up to 10 years. ${ }^{41}$

Most of the studies on mortality in osteoporotic fracture were centered on hip fracture. The high interest may have been spurred by reports that hip fracture patients have increased mortality rate compared with the general population. ${ }^{42,59,60}$ Five of the studies in this review focused on mortality related to hip fracture, ${ }^{45,47,48,50}$ while only one study focused on vertebral fracture. ${ }^{51}$ Ziadé et al ${ }^{49}$ and Bliuc et $\mathrm{a}^{46}$ examined all types of osteoporotic fractures.

Most of the study subjects were female since they were at higher risk of osteoporosis and related fractures. Ziadé et $a l^{49}$ reported that the mortality rate for hip fracture in France from 1968 to 2004 was higher in women but that the rate was dropping fast and lay close to the mortality rate for men by 2004. Other studies have reported that the risk of mortality after a hip fracture was higher in men than in women. ${ }^{45,48,50}$
According to one study, infectious diseases, including septicemia and pneumonia, accounted for the greatest increase in mortality in men after hip fracture. Confusion, pressure sores, congestive heart failure, and renal failure were also more common in men after hip fracture surgeries. ${ }^{61} \mathrm{In}$ a more recent study, the higher mortality in males could not be explained by the higher prevalence of chronic comorbidities or by differences in comedications. ${ }^{62}$ It is disturbing to learn that although life expectancy in general and survival from diseases such as stroke and myocardial infarction have improved, the same cannot be said for hip fracture. ${ }^{45}$

Since osteoporotic fracture are more common in the elderly, ${ }^{48}$ most of the studies were carried out on elderly subjects 65 years or older, except for Vestergaard et a ${ }^{45}$ who included younger subjects (however, the percentage of these younger patients was only close to $13 \%$ and would not have changed the results if they were left out from the study). In an earlier study, it was reported that more than 32,000 people aged 65 years or over were admitted to hospital with fractured neck of femur between 1968 and $1998 .{ }^{44}$ Above 60 years old, mortality was increased for all fractures except for minor fractures, which were only apparent for patients older than 75 years. Increased mortality risk persisted for 5 years for all fractures and for up to 10 years for hip fractures. ${ }^{49}$

If osteoporotic fracture patients develop another fracture, their risk of mortality was increased in both sexes and remained higher than in the general population. Besides subsequent fracture, other predictors of mortality after an osteoporotic fracture, for both sexes, included age, quadriceps weakness, high ASA score, and low SPMSQ score. ${ }^{45,46}$ Exclusive predictors for women were low bone mineral density, having smoked, and postural sway, while that for men was low physical activity. ${ }^{46}$ The most common causes of death for osteoporotic fracture patients were circulatory diseases, followed by dementia and Alzheimer's disease. Men were more likely than women to die from respiratory disease, malignant neoplasm, and circulatory disease. ${ }^{51}$

Our systematic review has limitations. The aim of this systematic review was to determine the outcome and mortality of patients with osteoporotic fractures after their discharge from hospital. It was assumed that all the osteoporotic fracture-related mortality reported by the studies had occurred after hospital discharge. Most studies did not provide enough information on the place of death. Panula et $\mathrm{a}^{50}$ did mention the place of death, so it can be assumed that those who died outside the hospital could be classified as mortality after hospital discharge. About $25 \%$ of mortality 
occurred either at home, elderly care facility, or even at an unknown place, which could be considered as mortality after hospital discharge. The rest of deaths occurred in the hospital after they were readmitted due to other diseases, mainly circulatory, respiratory, gastrointestinal diseases, malignancy, or dementia.

\section{Conclusion}

Osteoporotic fracture patients are exposed to various adverse outcomes in terms of morbidity, subsequent fractures, and mortality after hospital discharge. Patients with an osteoporotic fracture suffer from high morbidity, increased risk of another fracture, and a high risk of mortality after hospital discharge. Awareness of these outcomes needs to be highlighted to ensure the smooth and rapid recovery of these patients.

\section{Acknowledgments}

The systematic review was supported by the Research Innovation Grant (grant number DIP-2013-002) of the University Kebangsaan Malaysia.

\section{Disclosure}

The authors report no conflicts of interest in this work.

\section{References}

1. Ben Sedrine W, Radican L, Reginster JY. On conducting burden-ofosteoporosis studies: a review of the core concepts and practical issues. A study carried out under the auspices of a WHO Collaborating Center. Rheumatology (Oxford). 2001;40(1):7-14.

2. Adachi JD, Ioannidis G, Pickard L, et al. The association between osteoporotic fractures and health-related quality of life as measured by the Health Utilities Index in the Canadian Multicentre Osteoporosis Study (CaMos). Osteoporos Int. 2003;14(11):895-904.

3. Johnell O, Kanis J. Epidemiology of osteoporotic fractures. Osteoporosis Int. 2005;16(Suppl 2):S3-S7.

4. Papaioannou A, Morin S, Cheung AM, et al; Scientific Advisory Council of Osteoporosis Canada. 2010 clinical practice guidelines for the diagnosis and management of osteoporosis in Canada: summary. CMAJ. 2010;182(17):1864-1873.

5. Melton LJ, Thamer M, Ray NF, et al. Fractures attributable to osteoporosis: report from the National Osteoporosis Foundation. J Bone Miner Res. 1997;12(1):16-23.

6. O’Neill TW, Roy DK. How many people develop fractures with what outcome? Best Pract Res Clin Rheumatol. 2005;19(6):879-895.

7. Jones G, Nguyen T, Sambrook PN, Kelly PJ, Gilbert C, Eisman JA. Symptomatic fracture incidence in elderly men and women: the Dubbo Osteoporosis Epidemiology Study (DOES). Osteoporos Int. 1994;4(5):277-282.

8. Melton LJ, Crowson CS, O'Fallon WM. Fracture incidence in Olmsted County, Minnesota: comparison of urban with rural rates and changes in urban rates over time. Osteoporos Int. 1999;9(1):29-37.

9. Miller W. Survival and ambulation following hip fracture. J Bone Joint Surg Am.1978;60(7):930-934.

10. Cummings SR, Kelsey JL, Nevitt MC, O’Dowd KJ. Epidemiology of osteoporosis and osteoporotic fractures. Epidemiol Rev. 1985;7: 178-208.
11. Jensen JS, Bagger J. Long-term social prognosis after hip fractures. Acta Orthop Scand. 1982;53(1):97-101.

12. Johnell O, Kanis JA. An estimate of the worldwide prevalence and disability associated with osteoporotic fractures. Osteoporos Int. 2006; 17(12):1726-1733.

13. Old JL, Calvert M. Vertebral compression fractures in the elderly. Am Fam Physician. 2004;69(1):111-116.

14. Kanis JA, Johnell O, Oden A, et al. Long-term risk of osteoporotic fracture in Malmö. Osteoporos Int. 2000;11(8):669-674.

15. Sakuma M, Endo N, Oinuma T, et al. Incidence and outcome of osteoporotic fractures in 2004 in Sado City, Niigata Prefecture, Japan. J Bone Miner Metab. 2008;26(4):373-378.

16. Majumdar SR, Kim N, Colman I, et al. Incidental vertebral fractures discovered with chest radiography in the emergency department: prevalence, recognition, and osteoporosis management in a cohort of elderly patients. Arch Intern Med. 2005;165(8):905-909.

17. Ross PD, Davis JW, Epstein RS, Wasnich RD. Pain and disability associated with new vertebral fractures and other spinal conditions. J Clin Epidemiol. 1994;47(3):231-239.

18. Leidig G, Minne HW, Sauer P, et al. A study of complaints and their relation to vertebral destruction in patients with osteoporosis. Bone Miner. 1990;8(3):217-229.

19. Greendale GA, Barrett-Connor E. Outcomes of osteoporotic fractures. In: Marcus R, Feldman D, Kelsey J, editors. Osteoporosis. 2nd ed. San Diego, CA: Academic Press. 2001;819-29.

20. Chrischilles EA, Butler CD, Davis CS, Wallace RB. A model of lifetime osteoporosis impact. Arch Intern Med. 1991;151(10):2026-2032.

21. Kaukonen JP, Karaharju EO, Porras M, Lüthje P, Jakobsson A. Functional recovery after fractures of the distal forearm. Analysis of radiographic and other factors affecting the outcome. Ann Chir Gynaecol. 1988;77(1):27-31.

22. Gold DT, Lyles KW, Shipp KM, Drezner MK. Osteoporosis and its nonskeletal consequences: their impact on treatment decisions. In: Marcus R, Feldman D, Kelsey J, editors. Osteoporosis. 2nd ed. San Diego, CA: Academic Press. 2001;479-84.

23. Cummings SR, Melton LJ. Epidemiology and outcomes of osteoporotic fractures. Lancet. 2002;359(9319):1761-1767.

24. Colón-Emeric CS, Saag KG. Osteoporotic fractures in older adults. Best Pract Res Clin Rheumatol. 2006;20(4):695-706.

25. Haentjens P, Lamraski G, Boonen S. Costs and consequences of hip fracture occurrence in old age: an economic perspective. Disabil Rehabil. 2005;27(18-19):1129-1141.

26. Brainsky A, Glick H, Lydick E, et al. The economic cost of hip fractures in community-dwelling older adults: a prospective study. J Am Geriatr Soc. 1997;45(3):281-287.

27. Wiktorowicz ME, Goeree R, Papaioannou A, Adachi JD, Papadimitropoulos E. Economic implications of hip fracture: health service use, institutional care and cost in Canada. Osteoporos Int. 2001;12(4):271-278.

28. Bouee S, Lafuma A, Fagnani F, Meunier PJ, Reginster JY. Estimation of direct unit costs associated with non-vertebral osteoporotic fractures in five European countries. Rheumatol Int. 2006;26(12):1063-1072.

29. Port L, Center J, Briffa NK, Nguyen T, Cumming R, Eisman J. Osteoporotic fracture: missed opportunity for intervention. Osteoporos Int. 2003;14(9):780-784.

30. Eisman J, Clapham S, Kehoe L; Australian BoneCare Study. Osteoporosis prevalence and levels of treatment in primary care: the Australian BoneCare Study. J Bone Miner Res. 2004;19(12):1969-1975.

31. Majumdar SR, Rowe BH, Folk D, et al. A controlled trial to increase detection and treatment of osteoporosis in older patients with a wrist fracture. Ann Intern Med. 2004;141(5):366-373.

32. Lindsay R. The burden of osteoporosis: cost. Am J Med.1995;98(2A): 9S-11S.

33. Ioannidis G, Papaioannou A, Hopman WM, et al. Relation between fractures and mortality: results from the Canadian Multicentre Osteoporosis Study. CMAJ. 2009;181(5):265-271. 
34. Kaffashian S, Raina P, Oremus M, et al; CaMos Research Group. The burden of osteoporotic fractures beyond acute care: the Canadian Multicentre Osteoporosis Study (CaMos). Age Ageing. 2011;40(5):602-607.

35. Siggeirsdottir K, Aspelund T, Jonsson BY, et al. Effect of vertebral fractures on function, quality of life and hospitalisation the AGESReykjavik study. Age Ageing. 2012;41(3):351-357.

36. Hallberg I, Rosenqvist AM, Kartous L, Löfman O, Wahlström O, Toss G. Health-related quality of life after osteoporotic fractures. Osteoporos Int. 2004;15(10):834-841.

37. Chen CW, Huang TL, Su LT, et al. Incidence of subsequent hip fractures is significantly increased within the first month after distal radius fracture in patients older than 60 years. J Trauma Acute Care Surg. 2013;74(1):317-321.

38. Lih A, Nandapalan H, Kim M, et al. Targeted intervention reduces refracture rates in patients with incident non-vertebral osteoporotic fractures: a 4-year prospective controlled study. Osteoporos Int. 2011; 22(3):849-858.

39. Lyles KW, Schenck AP, Colón-Emeric CS. Hip and other osteoporotic fractures increase the risk of subsequent fractures in nursing home residents. Osteoporos Int. 2008;19(8):1225-1233.

40. Hodsman AB, Leslie WD, Tsang JF, Gamble GD. 10-year probability of recurrent fractures following wrist and other osteoporotic fractures in a large clinical cohort: an analysis from the Manitoba Bone Density Program. Arch Intern Med. 2008;168(20):2261-2267.

41. Center JR, Bliuc D, Nguyen TV, Eisman JA. Risk of subsequent fracture after low-trauma fracture in men and women. JAMA. 2007;297(4): 387-394.

42. Johnell O, Kanis JA, Odén A, et al. Fracture risk following an osteoporotic fracture. Osteoporos Int. 2004;15(3):175-179.

43. Genant HK, Cooper C, Poor G, et al. Interim report and recommendations of the World Health Organization Task-Force for Osteoporosis. Osteoporos Int. 1999;10(4):259-264.

44. Roberts SE, Goldacre MJ. Time trends and demography of mortality after fractured neck of femur in an English population, 1968-1998: database study. BMJ. 2003;327(7418):771-775.

45. Vestergaard P, Rejnmark L, Mosekilde L. Has mortality after a hip fracture increased? J Am Geriatr Soc. 2007;55(11):1720-1726.

46. Bliuc D, Nguyen ND, Milch VE, Nguyen TV, Eisman JA, Center JR. Mortality risk associated with low-trauma osteoporotic fracture and subsequent fracture in men and women. JAMA. 2009;301(5):513-521.

47. Brauer CA, Coca-Perraillon M, Cutler DM, Rosen AB. Incidence and mortality of hip fractures in the United States. JAMA. 2009; 302(14):1573-1579.

48. Söderqvist A, Ekström W, Ponzer S, et al; Stockholm Hip Fracture Group. Prediction of mortality in elderly patients with hip fractures: a two-year prospective study of 1,944 patients. Gerontology. 2009;55(5):496-504.
49. Ziadé N, Jougla E, Coste J. Population-level impact of osteoporotic fractures on mortality and trends over time: a nationwide analysis of vital statistics for France, 1968-2004. Am J Epidemiol. 2010;172(8): 942-951.

50. Panula J, Pihlajamäki H, Mattila VM, et al. Mortality and cause of death in hip fracture patients aged 65 or older: a population-based study. BMC Musculoskelet Disord. 2011;12:105.

51. Kanis JA, Oden A, Johnell O, De Laet C, Jonsson B. Excess mortality after hospitalisation for vertebral fracture. Osteoporos Int. 2004; 15(2):108-112.

52. Laitinen P. Participation of caregivers in elderly-patient hospital care: informal caregiver approach. J Adv Nurs. 1993;18(9):1480-1487.

53. Sapountzi-Krepia D, Lavdaniti M, Psychogiou M, et al. Nursing staff shortage and in-hospital informal care in an oncology hospital in Greece: the nursing staff's perceptions. Int J Nurs Pract. 2008;14(3): 256-263.

54. Ström O, Borgstrom F, Zethraeus N, et al. Long-term cost and effect on quality of life of osteoporosis-related fractures in Sweden. Acta Orthop. 2008;79(2):269-280.

55. Bouza C, López T, Palma M, Amate JM. Hospitalised osteoporotic vertebral fractures in Spain: analysis of the national hospital discharge registry. Osteoporos Int. 2007;18(5):649-657.

56. Braithwaite RS, Col NF, Wong JB. Estimating hip fracture morbidity, mortality and costs. J Am Geriatr Soc. 2003;51(3):364-370.

57. van den Berg B, Brouwer WB, Koopmanschap MA. Economic valuation of informal care. An overview of methods and applications. Eur $J$ Health Econ. 2004;5(1):36-45

58. Wilson D, Truman C. Comparing the health services utilization of long-term-care residents, home-care recipients, and the well elderly. Can J Nurs Res. 2005;37(4):138-154.

59. Keene GS, Parker MJ, Pryor GA. Mortality and morbidity after hip fractures. BMJ. 1993;307(6914):1248-1250.

60. Kenzora JE, McCarthy RE, Lowell JD, Sledge CB. Hip fracture mortality. Relation to age, treatment, preoperative illness, time of surgery, and complications. Clin Orthop Relat Res. 1984;(186):45-56.

61. Wehren LE, Hawkes WG, Orwig DL, Hebel JR, Zimmerman SI, Magaziner J. Gender differences in mortality after hip fracture: the role of infection. J Bone Miner Res. 2003;18(12):2231-2237.

62. Kannegaard PN, van der Mark S, Eiken P, Abrahamsen B. Excess mortality in men compared with women following a hip fracture. National analysis of comedications, comorbidity and survival. Age Ageing. 2010;39(2):203-209.
Therapeutics and Clinical Risk Management

\section{Publish your work in this journal}

Therapeutics and Clinical Risk Management is an international, peerreviewed journal of clinical therapeutics and risk management, focusing on concise rapid reporting of clinical studies in all therapeutic areas, outcomes, safety, and programs for the effective, safe, and sustained use of medicines. This journal is indexed on PubMed Central, CAS,
Dovepress

EMBase, Scopus and the Elsevier Bibliographic databases. The manuscript management system is completely online and includes a very quick and fair peer-review system, which is all easy to use. Visit http://www.dovepress.com/testimonials.php to read real quotes from published authors. 